\title{
Carbonation of Circulating Fluidized Bed Boiler Fly Ash Using Carbonate Liquids
}

\author{
Woong-Geol Lee*, Jin-Eung Kim***, Se-Hoon Jeon*, , and Myong-Shin Song**, \\ *Department of Advanced Materials Engineering, Kangwon National University, Samcheock 25913, Korea \\ **Research Center of Advanced Convergence Processing on Materials, Kangwon National University, Samcheock 25913, Korea \\ ${ }^{* * *} R \& D$ Center Team, Intchem Co., Ltd., Yongin 17088, Korea
}

(Received April 13, 2017; Revised June 26, 2017; Accepted July 9, 2017)

\begin{abstract}
In this study, unstable $\mathrm{CaO}$ was converted into a stable Ca compound by using carbonation in a circulating fluidized bed boiler of fly ash to confirm material usability as cement admixture; also undertaken was carbonation test and mortar to examine chemical and physical change by measuring absorption rate and compressive strength. To investigate the chemical properties of circulating fluidized bed boiler fly ash, XRD and TG-DTA were used to determine how the properties of the reaction product change quantitatively during carbonation. In order to stabilize $\mathrm{CaO}$, carbonation of $\mathrm{CaO}$ is considered to be the most desirable process. This is because $\mathrm{CaCO}_{3}$, which is a $\mathrm{Ca}$ compound, was produced by carbonate reaction of unstable $\mathrm{CaO}$, and decrease of the absorption rate and improvement of the compressive strength were observed when the carbonated fly ash was replaced with cement.
\end{abstract}

Key words : Fluidized bed boiler fly ash, Calcium oxide, Free-CaO, Carbonation, Calcium carbonate

\section{Introduction}

$\mathrm{C}$ urrently, about 8 million tons of coal ash waste is discharged from thermoelectric power plants in Korea. ${ }^{1)}$ The most frequently used methods of combusting coal to produce energy at thermoelectric power plants are pulverized coal firing and circulating fluidized bed combustion. Due to the advantages of circulating fluidized bed combustion in comparison with pulverized coal firing, including a relatively low combustion temperature $\left(800\right.$ to $\left.900^{\circ} \mathrm{C}\right)$ to suppress the generation of nitrogen oxides $\left(\mathrm{NO}_{\mathrm{x}}\right)$ and the immediate desulfurization of limestone in the furnace, the number of thermoelectric power plants employing circulating fluidized bed combustion is gradually increasing. ${ }^{2)}$ As a result, fluidized bed fly ash generated from circulating fluidized bed combustion boilers is also increasing. The general fly ash generated from pulverized coal firing is often used as a mixing material for cement and concrete, because general fly ash mixed with cement and concrete by Pozzolanic reaction provides advantages such as increased long-term strength, decreased drying contraction, and excellent chemical resistance. ${ }^{3)}$ However, the application of fly ash from a fluidized bed as a mixing material for cement and concrete is limited because such fly ash may cause an early drastic

\footnotetext{
${ }^{\dagger}$ Corresponding author : Se-Hoon Jeon

E-mail : zine2421@naver.com

Tel : +82-33-570-6556 Fax : +82-33-570-6556

'Corresponding author : Myong-Shin Song

E-mail : msong0422@kangwon.ac.kr

Tel : +82-33-570-6556 Fax : +82-33-570-6556
}

heat release, cracks, and reduced fluidity due to free $\mathrm{CaO}$ resulting from the $\mathrm{CaO}$ and $\mathrm{SO}_{3}$ component remaining after the desulfurization. Therefore, to mix fly ash from a fluidized bed boiler with ordinary Portland cement (OPC), pure $\mathrm{CaO}$ needs to be stabilized. Generally, the carbonation of pure $\mathrm{CaO}$ involves the reactions of Equation (1) and (3) occurring consecutively along with mixing with an aqueous carbonate solution or the production of carbonate by the reaction of Equation (3):

$$
\begin{aligned}
& \mathrm{CaO}+\mathrm{H}_{2} \mathrm{O} \rightarrow \mathrm{Ca}(\mathrm{OH})_{2}(\text { Hydration }) \\
& \mathrm{CaO}(\text { or free- } \mathrm{CaO})+\mathrm{CO}_{2} \rightarrow \boldsymbol{C a} \boldsymbol{C O} \boldsymbol{O}_{3} \text { (Carbonation I) } \\
& \mathrm{Ca}(\mathrm{OH})_{2}+\mathrm{CO}_{2} \rightarrow \boldsymbol{C a} \boldsymbol{C O}_{3}+\mathrm{H}_{2} \mathrm{O} \text { (Carbonation II) }
\end{aligned}
$$

When $\mathrm{Na}_{2} \mathrm{CO}_{3}$ or $\mathrm{K}_{2} \mathrm{CO}_{3}$, used in the present study, is involved, $1 \mathrm{M}$ of $\mathrm{CaO}$ requires $1 \mathrm{M}$ of $\mathrm{CO}_{2}$, as shown in Equation (4). When $\mathrm{Na}_{2} \mathrm{CO}_{3}$ or $\mathrm{K}_{2} \mathrm{CO}_{3}$ is dissolved in water, as in Equation (5), as one mol of $\mathrm{CO}_{2}$ is dissociated (I), $\mathrm{NaOH}$ and $\mathrm{NaHCO}_{3}$ are dissolved in water. When the reaction further progresses, $\mathrm{CaO}$ reacts with $\mathrm{CO}_{2}$ or $\mathrm{NaHCO}_{3}$ dissolved in water to produce $\mathrm{CaCO}_{3}$, as shown in Equation (6). According to the theoretical stoichiometry, complete carbonation of one mol $\mathrm{CaO}$ requires one mol of $\mathrm{Na}_{2} \mathrm{CO}_{3}$ or $\mathrm{K}_{2} \mathrm{CO}_{3}$.

$$
\begin{aligned}
\mathrm{CaO}+\mathrm{CO}_{2} \rightarrow \mathrm{CaCO}_{3} & \\
\mathrm{Na}_{2} \mathrm{CO}_{3}\left(\text { or } \mathrm{K}_{2} \mathrm{CO}_{3}\right)+\mathrm{H}_{2} \mathrm{O} & \rightarrow 2 \mathrm{Na}(\text { or } \mathrm{K}) \mathrm{OH}+\mathrm{CO}_{2}(\mathrm{I}) \\
& \rightarrow \mathrm{NaOH}+\mathrm{NaHCO}_{3}(\mathrm{II}) \\
\mathrm{NaOH}+\mathrm{NaHCO}_{3}+\mathrm{CaO} & \rightarrow 2 \mathrm{NaOH}+\mathrm{CaCO}_{3}
\end{aligned}
$$

Therefore, in the present study, the optimal conditions of 
carbonation (the kinds and concentrations of aqueous carbonate solution, the reaction time, and the free $\mathrm{CaO}$ content) were established for easy carbonation through simple chemical reactions to convert $\mathrm{CaO}$ existing in large amounts in fly ash from circulating fluidized bed boilers to chemically stable Ca compounds, such as $\mathrm{CaCO}_{3}$ and $\mathrm{Ca}(\mathrm{OH})_{2}$, through the carbonation of an aqueous carbonate solution. In addition, to measure the properties of the cement mortar, the circulating fluidized bed boiler fly ash to which the optimized carbonation was applied was mixed with cement mortar.

\section{Experimental Procedure}

\subsection{Materials}

Fly ash used in the present study was fluidized bed boiler fly ash (FBA), a side product from a circulating fluidized bed boiler at the "Y" thermoelectric power plant in Korea; ash has a specific surface area of $4070 \mathrm{~cm}^{2} / \mathrm{g}$ and a specific weight of 2.60. Table 1 shows the chemical composition of the FBA containing about $19 \%$ of free $\mathrm{CaO}$. Fig. 1 shows the results of X-ray diffraction (XRD) analysis of the FBA. The XRD results show that the main components of the FBA were lime $(\mathrm{CaO})$, anhydrite $\left(\mathrm{CaSO}_{4}\right)$, and quartz $\left(\mathrm{SiO}_{2}\right)$; the FBA also contained other compounds such as periclase $(\mathrm{MgO})$, portlandite $\left(\mathrm{Ca}(\mathrm{OH})_{2}\right)$, and calcite $\left(\mathrm{CaCO}_{3}\right)$. Fig. 2 shows the thermogravimetric-differential thermal analysis (TG-DTA) results for the FBA, indicating that the endothermal peaks and the weight decreased at 100,450 and $750^{\circ} \mathrm{C}$. The decrease of the weight may have been due to the evaporation of free water at $100^{\circ} \mathrm{C}$, the degradation of $\mathrm{Ca}(\mathrm{OH})_{2}$ to $\mathrm{CaO}$ and $\mathrm{H}_{2} \mathrm{O}$ at $450^{\circ} \mathrm{C}$, and the degradation of $\mathrm{CaCO}_{3}$ to $\mathrm{CaO}$ and $\mathrm{CO}_{2}$ at $750^{\circ} \mathrm{C}$. An aqueous carbonate solution needed for oxidation was prepared using reagent grade $\mathrm{Na}_{2} \mathrm{CO}_{3}$ and $\mathrm{K}_{2} \mathrm{CO}_{3}$. The cement for the analysis of the properties used in the present study was an OPC produced by

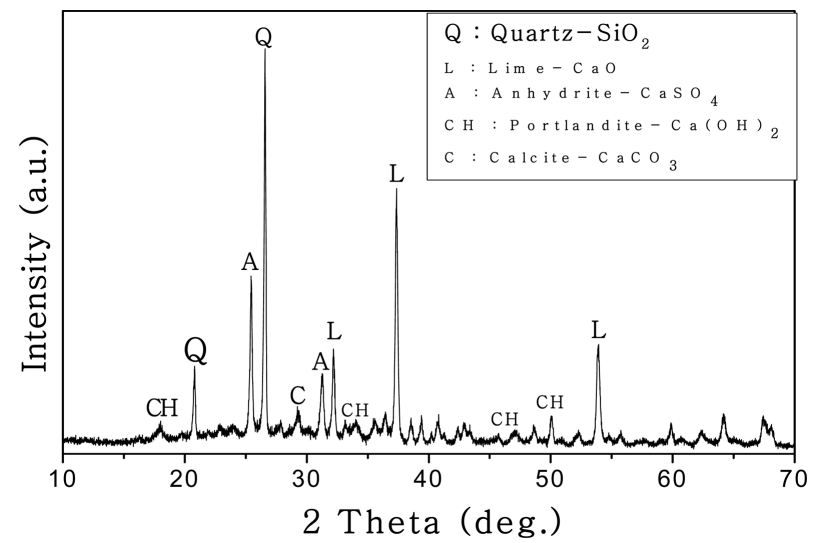

Fig. 1. XRD pattern of FBA.

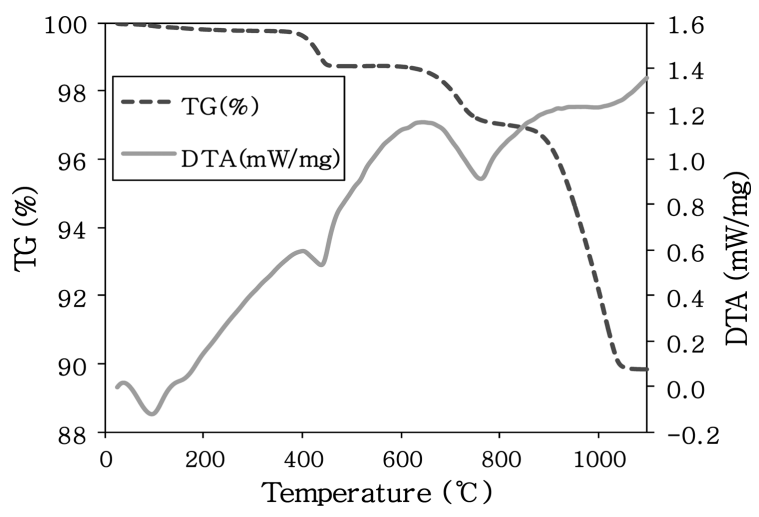

Fig. 2. TG-DTA results of FBA.

the "S" company. The fine aggregate used in the present study was Jumunjin standard sand.

\subsection{Methods}

2.2.1. Experiment for determining reaction mixing water ratio

FBA, containing a large amount of $\mathrm{CaO}$ and $\mathrm{CaSO}_{4}$, is known to show a high initial reactivity when mixed with water. ${ }^{4)}$ The high reactivity stems from free $\mathrm{CaO}$ contained in the FBA; the free $\mathrm{CaO}$ is the main target of carbonation. By considering the reaction time, the rate of reaction of the reactants FBA and purified distilled water was investigated to determine the mixing water ratio. In the experiment, mixing was performed for three minutes using a vibration mortar mixer; times of mixing were $1 \mathrm{~min}$ and $30 \mathrm{sec}$ at Rate 1 and $1 \mathrm{~min}$ and $30 \mathrm{sec}$ at Rate 2 . The mixture was kept in air for $1 \mathrm{~h}$ to verify the initial reactivity, and then dried in a dryer at $105^{\circ} \mathrm{C}$ for $24 \mathrm{~h}$. After drying, the weight was measured again to verify the maximum ratio of the mixing water that may react with FBA. The rate of reaction of the reactants in the experiment was obtained by calculating the difference between the dried sample weight $\left(\mathrm{W}_{105}\right)$ and the initial sample weight $\left(\mathrm{W}_{\mathrm{s}}\right)$, which was then divided by the initial sample weight $\left(\mathrm{W}_{\mathrm{s}}\right)$ and multiplied by 100 , as shown in the following Equation (7):

$$
\text { Rate of reactants }(\%)=\frac{W_{105}-W_{s}}{W_{s}} \times 100
$$

where $\mathrm{W}_{\mathrm{s}}=$ the initial sample weight and $\mathrm{W}_{105}=$ the dried sample weight $\left(105^{\circ} \mathrm{C}, 24 \mathrm{~h}\right)$.

Table 2 shows the reaction mixing water ratio used in the experiment.

\subsubsection{Carbonation of FBA}

The effective components from which $\mathrm{CO}_{2}$ may be

Table 1. Chemical Composition of a General FBA

\begin{tabular}{ccccccccc}
\hline $\mathrm{CaO}$ (free-CaO) & $\mathrm{SiO}_{2}$ & $\mathrm{Al}_{2} \mathrm{O}_{3}$ & $\mathrm{Fe}_{2} \mathrm{O}_{3}$ & $\mathrm{~K}_{2} \mathrm{O}$ & $\mathrm{TiO}_{2}$ & $\mathrm{MgO}$ & $\mathrm{SO}_{3}$ & $\mathrm{Ig}$. loss \\
\hline $30.7(19.4)$ & 36.2 & 16.8 & 5.2 & 1.5 & 0.7 & 4.1 & 0.9 & 3.87 \\
\hline
\end{tabular}


Table 2. Mixing Proportions of Reaction Mixed Water

\begin{tabular}{cccc}
\hline \multirow{2}{*}{ Type } & \multicolumn{2}{c}{ Mixing ratio (wt.\%) } & $\begin{array}{c}\text { Reaction time } \\
(\mathrm{h})\end{array}$ \\
\cline { 2 - 3 } & FBA & Water (D.I) & \\
\hline FBA-0.1 & & 10 & \\
FBA-0.2 & & 20 & 1 \\
FBA-0.3 & 100 & 30 & \\
FBA-0.4 & & 40 & \\
FBA-0.5 & & 50 & \\
\hline
\end{tabular}

absorbed and captured chemically were alkaline salts such as $\mathrm{CaO}, \mathrm{MgO}, \mathrm{Na}_{2} \mathrm{O}$, and $\mathrm{K}_{2} \mathrm{O} ; \mathrm{CO}_{2}$ can be captured from these reactants after they are converted to hydrate salts in an aqueous solution. ${ }^{5)}$ The unstable $\mathrm{CaO}$ contained in FBA at a high ratio was converted to stable $\mathrm{Ca}$ compounds $\left(\mathrm{CaCO}_{3}\right.$ or $\left.\mathrm{Ca}(\mathrm{OH})_{2}\right)$ through the binding with $\mathrm{CO}_{2}$ that had been dissociated from an aqueous carbonate solution. In the experiment, the production of $\mathrm{Ca}$ compounds and their yields were investigated by varying the experimental variables, including the kind of aqueous carbonate solution $\left(\mathrm{Na}_{2} \mathrm{CO}_{3}, \mathrm{~K}_{2} \mathrm{CO}_{3}\right.$ solution), the molar concentration (0, 0.5, $1.0,2.0$, and $3.0 \mathrm{~mol} / \mathrm{L})$, and the reaction time $(0,1,2$, and 4 $\mathrm{hr}$ ). Table 3 shows the carbonation conditions and the vari- ables. Table 4 shows the mixing ratios for the carbonation.

\subsubsection{Analysis of properties}

Drying and sieving were performed to analyze the products of the carbonation. In the analysis of the properties, for a qualitative analysis of the crystal structure of the minerals produced by the carbonation, XRD analysis was performed at $2 \theta$ values in a range of $5^{\circ}$ to $80^{\circ}$ at a heating rate of $4 \% \mathrm{~min}$. The XRD - Rietveld method was applied to qualitatively identify the produced $\mathrm{Ca}$ compounds. In addition, to quantify the $\mathrm{Ca}$ compounds $\left(\mathrm{Ca}(\mathrm{OH})_{2}, \mathrm{CaCO}_{3}\right)$ produced by the reaction of FBA with an aqueous solution, and to measure the thermal properties, TG-DTA was performed by increasing the temperature at a rate of $10^{\circ} \mathrm{C} / \mathrm{min}$ up to $1100^{\circ} \mathrm{C}$ while injecting $\mathrm{N}_{2}$ gas, an inert gas, at a constant rate of $50 \mathrm{ml} / \mathrm{min}$.

2.2.4. Measurement of water absorption of FBA-mixed mortar

Generally, free $\mathrm{CaO}$ stabilized using water is converted to $\mathrm{Ca}(\mathrm{OH})_{2}$. Application of $\mathrm{Ca}(\mathrm{OH})_{2}$ to OPC mortar increases the water absorption of the mortar and decreases the compressive strength. Therefore, to investigate the effect of carbonated FBA (C-FBA) on the OPC mortar, the water

Table 3. Experimental Method

\begin{tabular}{|c|c|c|c|c|}
\hline \multicolumn{3}{|c|}{ Type } & Evaluation items & Leveis \\
\hline \multirow{5}{*}{$\begin{array}{l}\text { Carbonate reaction } \\
\text { of Fly ash }\end{array}$} & \multicolumn{2}{|c|}{ Carbonate aqueous solution } & $\mathrm{Na}_{2} \mathrm{CO}_{3}, \mathrm{~K}_{2} \mathrm{CO}_{3}$ & 2 \\
\hline & \multicolumn{2}{|c|}{ Mixed water ratio (\%) } & 30 & 1 \\
\hline & \multicolumn{2}{|c|}{ Molarity (mol/L) } & $0.5,1.0,2.0,3.0$ & 4 \\
\hline & \multicolumn{2}{|c|}{ Reaction time (hr) } & $1,2,4$ & 3 \\
\hline & \multicolumn{2}{|c|}{ Characterization } & XRD-(Rietveld), TG-DTA & 2 \\
\hline \multirow{5}{*}{ Mortar test of Fly ash } & \multicolumn{2}{|c|}{$\mathrm{W} / \mathrm{B}(\%)$} & \multicolumn{2}{|c|}{0.5} \\
\hline & \multirow{2}{*}{ Binder } & Cement & \multicolumn{2}{|c|}{$\mathrm{OPC}$} \\
\hline & & Fly Ash & \multicolumn{2}{|c|}{ FBA, " C-FBA } \\
\hline & \multicolumn{2}{|c|}{ FBA (\%) } & \multicolumn{2}{|c|}{0,10} \\
\hline & \multicolumn{2}{|c|}{ Check items } & \multicolumn{2}{|c|}{ Compressive strength Water absorption } \\
\hline
\end{tabular}

*C-FBA : Carbonated FBA

Table 4. Mixing Proportions of Carbonation

\begin{tabular}{|c|c|c|c|c|c|c|c|c|c|}
\hline \multirow{3}{*}{ Type } & \multicolumn{9}{|c|}{ Mixing ratio (wt.\%) } \\
\hline & \multirow{2}{*}{ FBA } & \multicolumn{4}{|c|}{$\mathrm{Na}_{2} \mathrm{CO}_{3}$ solution } & \multicolumn{4}{|c|}{$\mathrm{K}_{2} \mathrm{CO}_{3}$ solution } \\
\hline & & $0.5 \mathrm{M}$ & $1.0 \mathrm{M}$ & $2.0 \mathrm{M}$ & $3.0 \mathrm{M}$ & $0.5 \mathrm{M}$ & $1.0 \mathrm{M}$ & $2.0 \mathrm{M}$ & $3.0 \mathrm{M}$ \\
\hline FBA-N0.5 & \multirow{8}{*}{100} & 0.3 & & & & & & & \\
\hline FBA-N1.0 & & & 0.3 & & & & & & \\
\hline FBA-N2.0 & & & & 0.3 & & & & & \\
\hline FBA-N3.0 & & & & & 0.3 & & & & \\
\hline FBA-K0.5 & & & & & & 0.3 & & & \\
\hline FBA-K1.0 & & & & & & & 0.3 & & \\
\hline FBA-K2.0 & & & & & & & & 0.3 & \\
\hline FBA-K3.0 & & & & & & & & & 0.3 \\
\hline
\end{tabular}


Table 5. Mixing Proportions of Mortar

\begin{tabular}{cccccc}
\hline \multirow{2}{*}{ Type } & \multicolumn{3}{c}{ Binder (wt.\%) } & \multirow{2}{*}{ W/B } & \multirow{2}{*}{ S/B } \\
\cline { 2 - 4 } & OPC & FBA & C-FBA & & \\
\hline OPC & 100 & & & & \\
FBA $10 \%$ & 90 & 10 & & 0.5 & 3.0 \\
C-FBA $10 \%$ & 90 & & 10 & & \\
\hline
\end{tabular}

absorption of the mortar was measured in the experiment according to the KS F 4419 method. Rectangular columnshaped specimens $(40 \times 40 \times 160 \mathrm{~mm})$ were prepared according to KS L ISO 679 and dried at $105^{\circ} \mathrm{C}$ for $24 \mathrm{~h}$; specimens were then cooled at room temperature for $4 \mathrm{~h}$. The cooled specimens were weighed and then immersed in water for 24 h. Then, after removing the water on the surface, the specimens were weighed to measure the water absorption depending on the mixing ratio. The water absorption was calculated by the following equation:

$$
\text { Water Absorption }(\%)=\frac{W_{s d}-W_{d}}{W_{d}}
$$

where $\mathrm{W}_{\mathrm{d}}$ denotes the weight of a cooled specimen and $\mathrm{W}_{\mathrm{sd}}$ the weight of a specimen after removing the water on the surface.

2.2.5. Measurement of compressive strength of FBA-mixed mortar

In order to examine the feasibility of using carbonated FBA (CFBA) as an OPC substitution material, part of the OPC was replaced by CFBA. Specimens were prepared according to the cement compressive strength test method of KS L ISO 679. The specimens were de-molded after $24 \mathrm{~h}$. The prepared specimens underwent water curing at $20 \pm$ $2^{\circ} \mathrm{C}$, and the compressive strength of the specimens was measured at the material ages of 3,7 , and 28 days. Table 5 shows the mixing ratios of the specimens prepared to measure the physical properties.

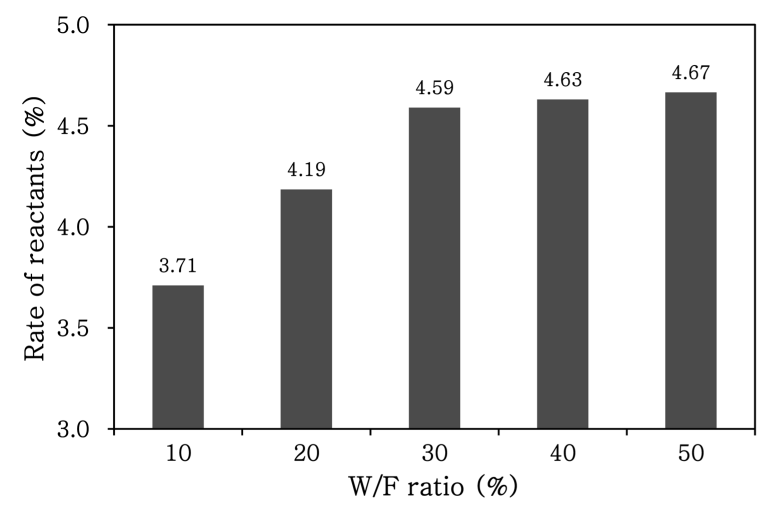

(a) Semi reactant rate of mixed water

\section{Results and Discussion}

\subsection{Determination of reaction mixing water ratio}

An experiment was performed to determine the reaction mixing water ratio for FBA. The experiment was performed to measure the quantity of water lost by the evaporation of the mixing water due to the drastic exothermic reaction during the mixing of the free $\mathrm{CaO}$ contained in the FBA with water, as well as the quantity of water needed for stabilization of the free $\mathrm{CaO}$. Fig. 3(a) is a plot showing the rate of reaction of the reactants depending on the quantity of the reaction mixing water. As the ratio of the reaction mixing water increased, the rate of reactants increased and then remained at a constant value after the ratio of the reaction mixing water was increased to over $30 \%$. Since the heat of reaction of the $\mathrm{CaO}$ decreased as the ratio of the reaction mixing water increased, the rate of the hydration reactants remained in a range of $4.5 \%$ to $4.7 \%$ without large variation. Fig. 3(b) is a plot showing the XRD results obtained by performing the carbonation of FBA by varying the reaction mixing water ratio between $30 \%$ and $50 \%$ using only water. Even when the ratio of the reaction mixing water increased, the intensity of the $\mathrm{CaCO}_{3}$ peak at a $2 \theta$ value of $29.3^{\circ}$ did not change. Thus, in the present study, the optimal ratio of the reaction mixing water was determined to be $30 \%$ for the carbonation of FBA. However, since the ratio was determined on the basis of the amount of free $\mathrm{CaO}$ contained in the FBA used in the present study, the optimal ratio of the reaction mixing water may be different if the amount of the free $\mathrm{CaO}$ is different in other samples.

\subsection{Effect of reaction time on carbonation}

Figure 4 shows the XRD results depending on the reaction time after the initiation of the carbonation of FBA at a ratio of reaction mixing water of $30 \%$ when $0.5 \mathrm{M}$ of $\mathrm{Na}_{2} \mathrm{CO}_{3}$ and $\mathrm{K}_{2} \mathrm{CO}_{3}$ aqueous solutions were used. The XRD plot for the FBA that underwent a reaction with the $0.5 \mathrm{M} \mathrm{Na}_{2} \mathrm{CO}_{3}$ aqueous solution shows that the intensity of the $\mathrm{CaCO}_{3}$ peak increased but that of the $\mathrm{Ca}(\mathrm{OH})_{2}$ peak decreased as

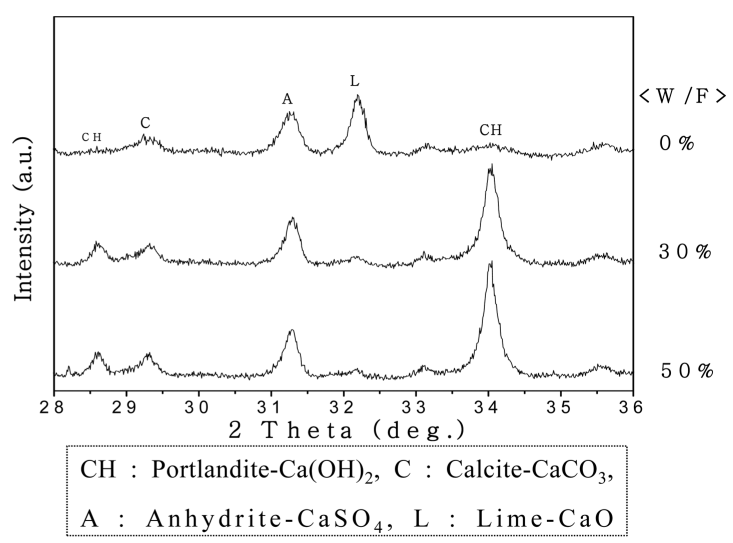

(b) XRD patterns of FBA by $\mathrm{W} / \mathrm{F}$ ratio

Fig. 3. Semi reactant rate of water according to the reaction of a mixed water and XRD patterns of FBA showing W/F ratio. 


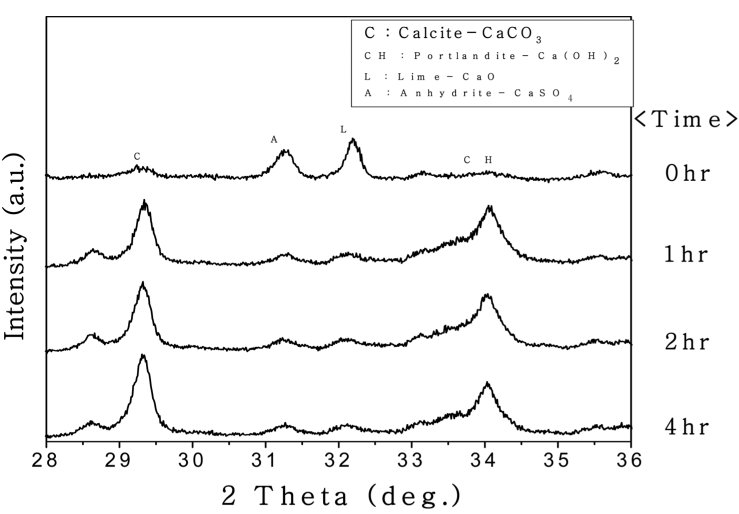

(a) $\mathrm{Na}_{2} \mathrm{CO}_{3} 0.5 \mathrm{M}$

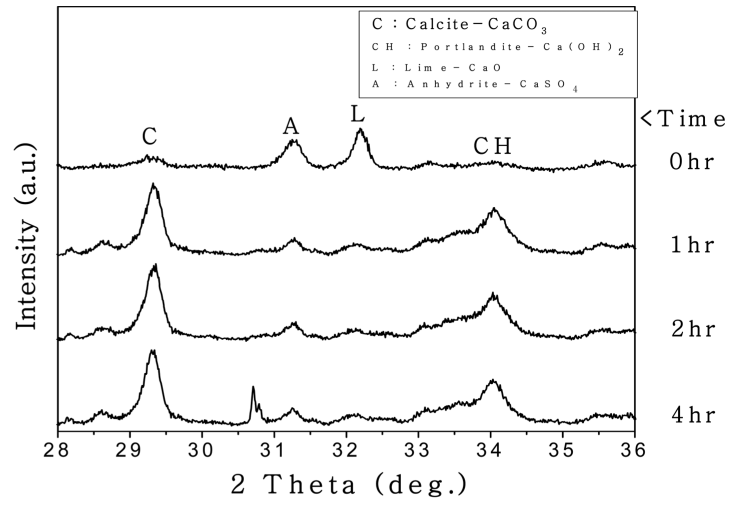

(b) $\mathrm{K}_{2} \mathrm{CO}_{3} 0.5 \mathrm{M}$

Fig. 4. Change of XRD peak height at 2 theta $29.3^{\circ}$ and XRD patterns of carbonated FBA with different reaction times.

the reaction time increased. The XRD plot for the FBA that underwent a reaction with the $0.5 \mathrm{M} \mathrm{K}_{2} \mathrm{CO}_{3}$ aqueous solution also shows that the intensity of the $\mathrm{CaCO}_{3}$ peak increased as the reaction time increased, with the highest intensity found at the reaction time of $4 \mathrm{~h}$. Fig. 4 shows the intensity of the $\mathrm{CaCO}_{3}$ peak at a $2 \theta$ value of $29.3^{\circ}$ depending on the aqueous carbonate solution. The intensity of the peak increased as the reaction time increased. The effect of the reaction time on the carbonation was not significant after 1 h. Thus, the optimal reaction time was considered to be $1 \mathrm{~h}$. On the other hand, in the FAB-N0.5 specimen with the lowest $\mathrm{K}_{2} \mathrm{CO}_{3}$ concentration, calcite was the most produced material, indicating that more calcite may be produced at a low concentration than at a high concentration because the reaction with free $\mathrm{CaO}$ may sufficiently occur at low concentration. Additional kinetic analysis may be required to determine the concentration and the reaction time.

\subsection{Effect of molar concentration on carbonation}

Figure 5 shows the results of XRD at a $2 \theta$ value of $28^{\circ}$, where the main peaks of the product pattern are identified. For the carbonation of FBA performed with the aqueous carbonate solutions, the intensity of the $\mathrm{CaO}$ and $\mathrm{Ca}(\mathrm{OH})_{2}$ peaks decreased but that of the $\mathrm{CaCO}_{3}$ increased as the molar concentration of the aqueous solution increased. Fig. 6 shows the yields of the Ca compounds depending on the kind of aqueous carbonate solution; results were determined by XRD - Rietveld method; the patterns of the yields were similar. In the case of the aqueous solution of $\mathrm{Na}_{2} \mathrm{CO}_{3}$, the $\mathrm{CaCO}_{3}$ yield was highest at $27.1 \mathrm{wt} \%$ when the molar concentration of the aqueous $\mathrm{Na}_{2} \mathrm{CO}_{3}$ solution was $0.5 \mathrm{M}$; the yield decreased as the molar concentration increased. In the case of the aqueous solution of $\mathrm{K}_{2} \mathrm{CO}_{3}$, the $\mathrm{CaCO}_{3}$ yield increased as the molar concentration increased, and the highest yield of $27.8 \mathrm{wt} \%$ was found at $3 \mathrm{M}$. Fig. 7 shows the qualitative verification of the production of $\mathrm{CaCO}_{3}$ on the basis of the weight decrease of the carbonated FBA, as analyzed by TG-DTA. The total ratio of the weight decrease was $18.8 \%$ when the aqueous $\mathrm{K}_{2} \mathrm{CO}_{3}$ solution was used; this decrease was about $0.4 \%$ higher than the case in which the aqueous $\mathrm{Na}_{2} \mathrm{CO}_{3}$ solution was used (18.4\%). In the decarbonation of $\mathrm{CaCO}_{3}$, the weight changes due to thermal degradation occurring in a temperature range of 700 to $800^{\circ} \mathrm{C}$, as the $\mathrm{CaCO}_{3}$ is degraded to $\mathrm{CaO}$ and $\mathrm{CO}_{2}$. Thus, a high weight decrease ratio means the production of a large amount of $\mathrm{CaCO}_{3}$. The ratio of the weight decrease was

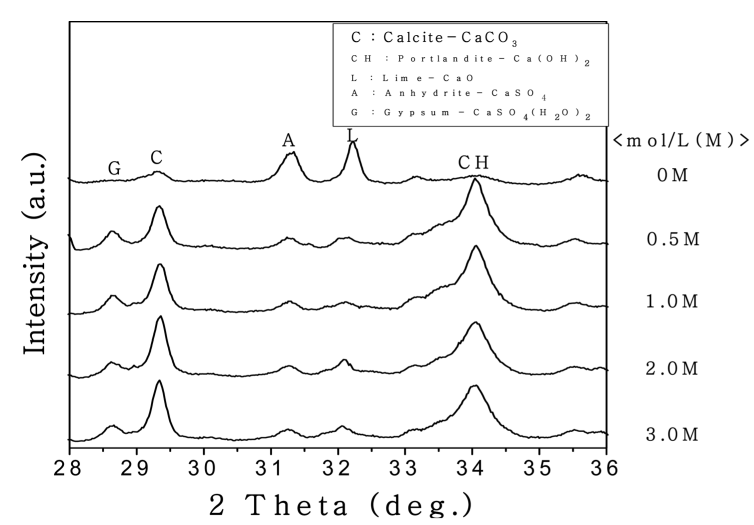

(a) $\mathrm{Na}_{2} \mathrm{CO}_{3}$ solution

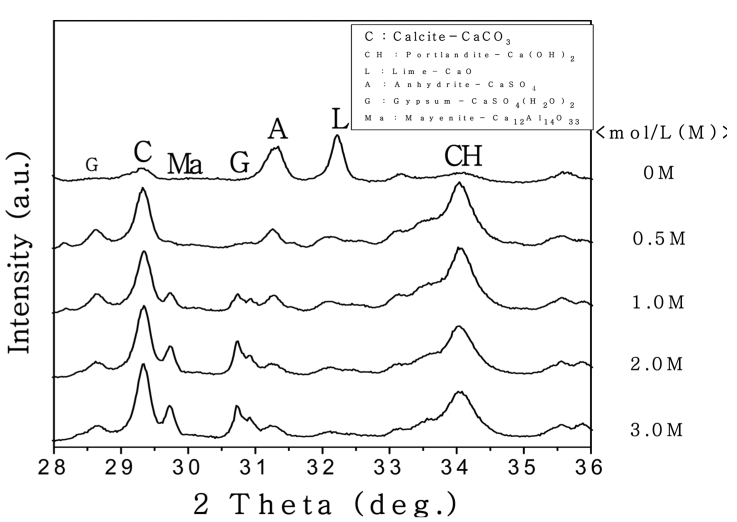

(b) $\mathrm{K}_{2} \mathrm{CO}_{3}$ solution

Fig. 5. XRD patterns according to molarity of carbonate aqueous solution. 


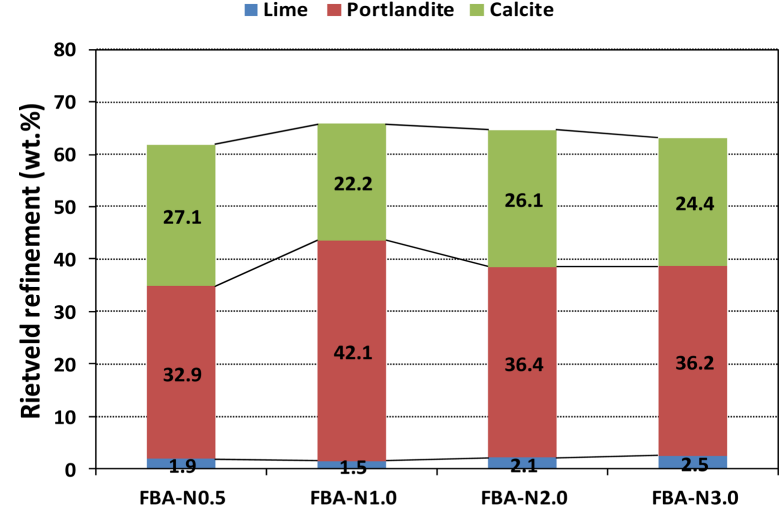

(a) $\mathrm{Na}_{2} \mathrm{CO}_{3}$ solution of carbonation

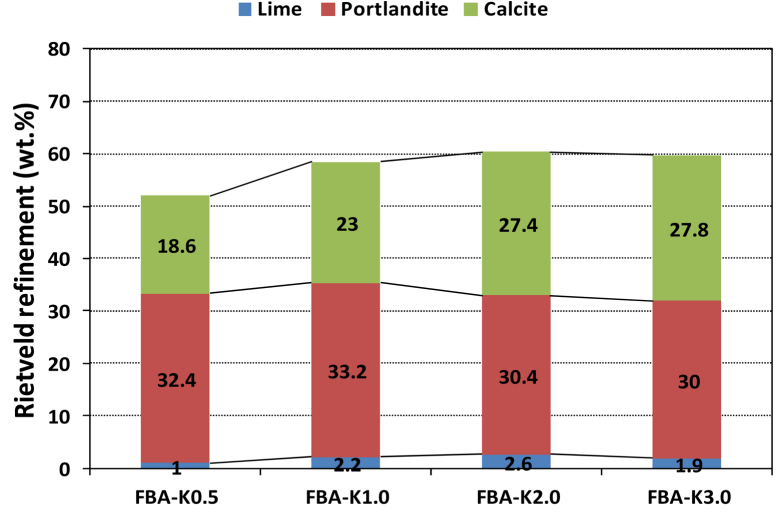

(b) $\mathrm{K}_{2} \mathrm{CO}_{3}$ solution of carbonation

Fig. 6. Comparison of amount of $\mathrm{Ca}$ compounds in each carbonate aqueous solution.

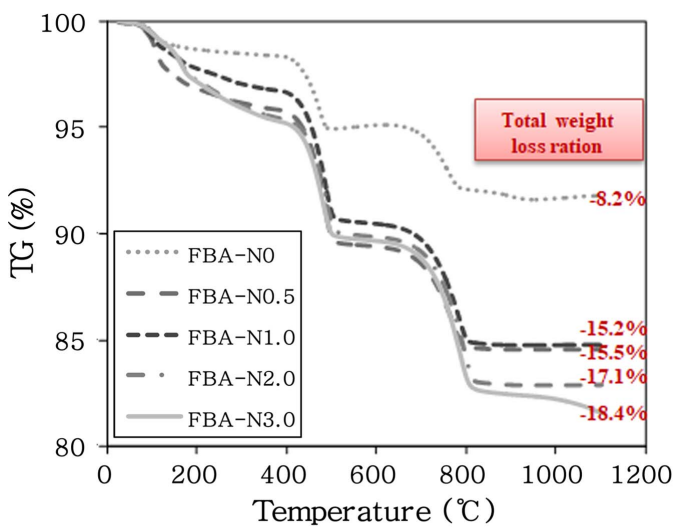

(a) $\mathrm{Na}_{2} \mathrm{CO}_{3}$ solution

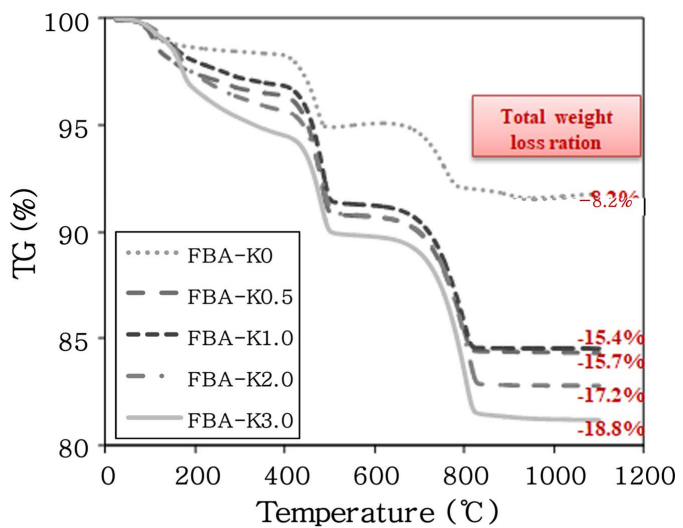

(b) $\mathrm{K}_{2} \mathrm{CO}_{3}$ solution

Fig. 7. TG curves of carbonated FBA with different solution and molarity.

$8.65 \%$ when a $3 \mathrm{M}$ aqueous $\mathrm{K}_{2} \mathrm{CO}_{3}$ solution was used and $7.27 \%$ when a $3 \mathrm{M}$ aqueous $\mathrm{Na}_{2} \mathrm{CO}_{3}$ solution was used, indicating that the ratio of the weight decrease was $1.38 \%$ higher when a $3 \mathrm{M}$ aqueous $\mathrm{K}_{2} \mathrm{CO}_{3}$ solution was used. This indicates that more $\mathrm{CaCO}_{3}$ was produced by the carbonation performed using a $3 \mathrm{M}$ aqueous $\mathrm{K}_{2} \mathrm{CO}_{3}$ solution than by the carbonation using a $3 \mathrm{M}$ aqueous $\mathrm{Na}_{2} \mathrm{CO}_{3}$ solution. This was because $\mathrm{K}^{+}$ions, having a weaker electrostatic attractive force and a higher ionization energy, were dissociated more in the aqueous solution and provided a condition that was more advantageous for the production of $\mathrm{CaCO}_{3}$, because free $\mathrm{CaO}$ may undergo a reaction more easily in the presence of more dissociated carbonate ions or at a higher molar concentration of a $\mathrm{CO}_{2}$ carbonate solution.

\subsection{Effect of $\mathrm{Na}^{+}$and $\mathrm{K}^{+}$ions on Ca compounds}

Figure 8 shows the XRD results of the C-FBA produced for $1 \mathrm{~h}$ of the reaction time and at a W/B ratio of 0.3 by using $3 \mathrm{M}$ aqueous $\mathrm{Na}_{2} \mathrm{CO}_{3}$ and $\mathrm{K}_{2} \mathrm{CO}_{3}$ solutions. The overall peak patterns are similar, but the intensity of the $\mathrm{CaCO}_{3}$ peak was higher when the carbonation was performed using a 3 $\mathrm{M}$ aqueous $\mathrm{K}_{2} \mathrm{CO}_{3}$ solution. The peak intensity of the C-FBA at a $2 \theta$ value of $29.3^{\circ}$ was higher when the carbonation was performed using an aqueous $\mathrm{K}_{2} \mathrm{CO}_{3}$ solution than it was when using an aqueous $\mathrm{Na}_{2} \mathrm{CO}_{3}$ solution. In addition, the peaks of mayenite, a calcium aluminate-based compound, and dihydrate gypsum $\left(\mathrm{CaSO}_{4} \cdot 2 \mathrm{H}_{2} \mathrm{O}\right)$, which is gypsum containing water molecules, were found around the $2 \theta$ values of $29.8^{\circ}$ and $30.7^{\circ}$. These compounds may have been produced by the reaction with free $\mathrm{CaO}$ that did not participate in the $\mathrm{CaCO}_{3}$ reaction. With regard to the effect of ions on the production of $\mathrm{CaCO}_{3}$, more $\mathrm{CO}_{3}{ }^{2-}$ ions may have been separated from the aqueous $\mathrm{K}_{2} \mathrm{CO}_{3}$ solution, because $\mathrm{K}^{+}$ions, having a longer nucleus-electron distance and thus a weaker nucleuselectron attraction in comparison with $\mathrm{Na}^{+}$ions, may lose electrons more easily and may undergo reaction with $\mathrm{CaO}$ (or free $\mathrm{CaO}$ ) more easily. Fig. 9 shows the TG results, indicating that more FBA weight was lost by the carbonation performed using a $3 \mathrm{M}$ aqueous $\mathrm{K}_{2} \mathrm{CO}_{3}$ solution when $\mathrm{CaCO}_{3}$ was degraded in a temperature range of 700 to $800^{\circ} \mathrm{C}$. Fig. 8 compares the intensity of the $\mathrm{CaCO}_{3}$ peaks at a $2 \theta$ value of $29.3^{\circ}$. The intensity of the $\mathrm{CaCO}_{3}$ peak was higher in the carbonation performed using a $3 \mathrm{M}$ aqueous $\mathrm{K}_{2} \mathrm{CO}_{3}$ solution. Therefore, for increasing the yield of $\mathrm{CaCO}_{3}$, a Ca-based 


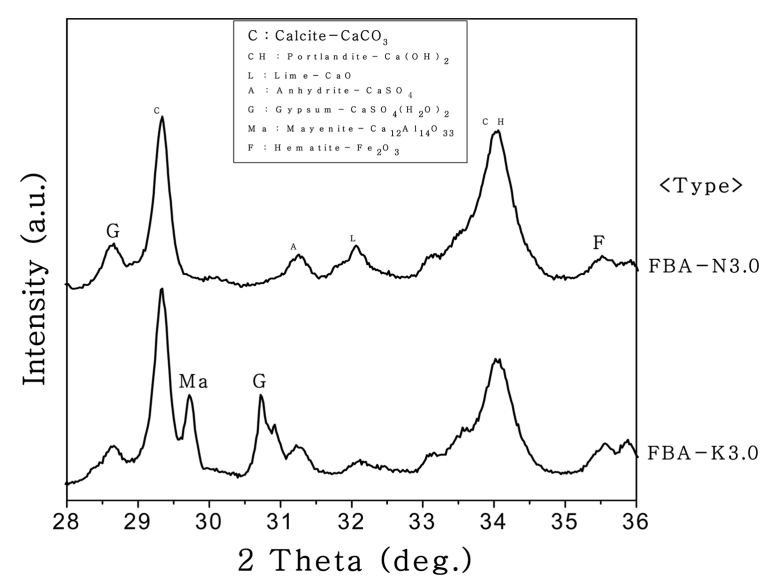

Fig. 8. XRD patterns of reactants determined by FBA-N3.0 and FBA-K3.0.

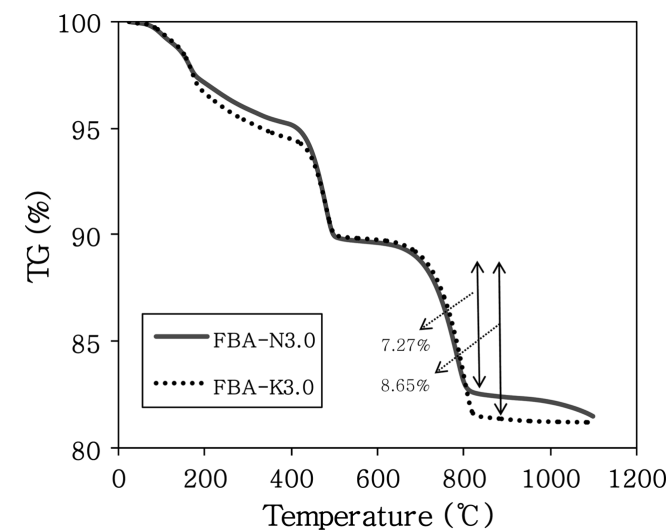

Fig. 9. TG curves of carbonated $\mathrm{FBA}$ of $\mathrm{Na}_{2} \mathrm{CO}_{3}$ and $\mathrm{K}_{2} \mathrm{CO}_{3}$ $3 \mathrm{M}$ solution.

compound, by the carbonation of $\mathrm{FBA}, \mathrm{K}^{+}$ion-based carbonate compounds have an advantage over $\mathrm{Na}^{+}$-based ions. To produce $\mathrm{CaCO}_{3}$, the optimal conditions for the carbonation may be the use of a $\mathrm{K}^{+}$ion-based carbonate compound, a reaction time of $1 \mathrm{~h}$, and a reaction mixing water ratio of $30 \%$.

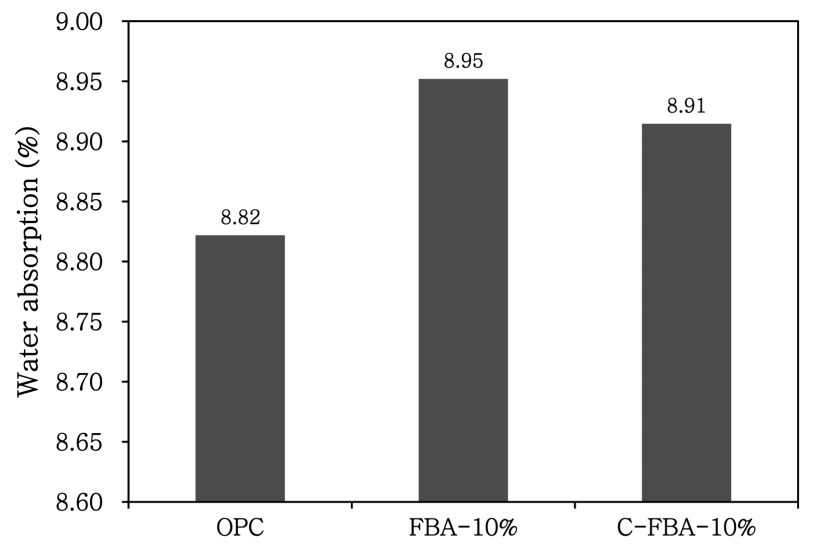

(a) Water absorption of mortar

Fig. 10. Water absorption and compressive strength of mortar.

\subsection{Properties of C-FBA mixed mortar}

Figure 10 compares the water absorption and the compressive strength of common OPC mortar and the mortars mixed with FBA or C-FBA. The water absorption was higher in FBA-mixed mortar than in the OPC mortar. The water absorption of the C-FBA-mixed mortar was lower than that of the conventional FBA-mixed mortar. This may be because the free $\mathrm{CaO}$ contained at a high ratio in the conventional FBA may have reacted with water to produce $\mathrm{Ca}(\mathrm{OH})_{2}$. This may have resulted in volumetric expansion of the FBA, which may have changed the internal pores and increased the water absorption. On the contrary, since a large amount of free $\mathrm{CaO}$ is converted in the carbonation through the reaction with carbonate to $\mathrm{CaCO}_{3}$, which is a stable compound, the C-FBA mixed with OPC to prepare mortar does not cause a significant change in the internal pores. Therefore, the water absorption of the C-FBA-mixed mortar was found to be about $0.04 \%$ lower than that of the conventional FBA-mixed mortar. The compressive strength values of the OPC mortar and the mortars prepared by mixing $10 \mathrm{wt} \%$ of FBA and C-FBA were measured at material ages of 3,7 , and 28 days. Generally, the compressive strength of the mortars prepared by mixing FBA and CFBA was lower than that of the OPC mortar. However, the compressive strength of the C-FBA-mixed mortar was higher than that of the FBA-mixed mortar. As the free $\mathrm{CaO}$ contained in the FBA underwent a rapid exothermic reaction and expansion, the internal pores may have increased, which may have resulted in cracks and reduced strength. On the contrary, as the unstable free $\mathrm{CaO}$ contained in the FBA was converted by carbonation to a stable Ca compound $\left(\mathrm{CaCO}_{3}\right)$ existing in C-FBA, the degree of the decrease of the compressive strength may have been reduced. In addition, the produced $\mathrm{CaCO}_{3}$ may have filled the internal pores of the OPC hydrates so that the compressive strength of the CFBA-mixed mortar is higher than that of the FBA-mixed mortar. ${ }^{6)}$ With reference to the material age of 28 days, the compressive strength values of the FBA-mixed mortar and the C-FBA-mixed mortar were respectively approximately

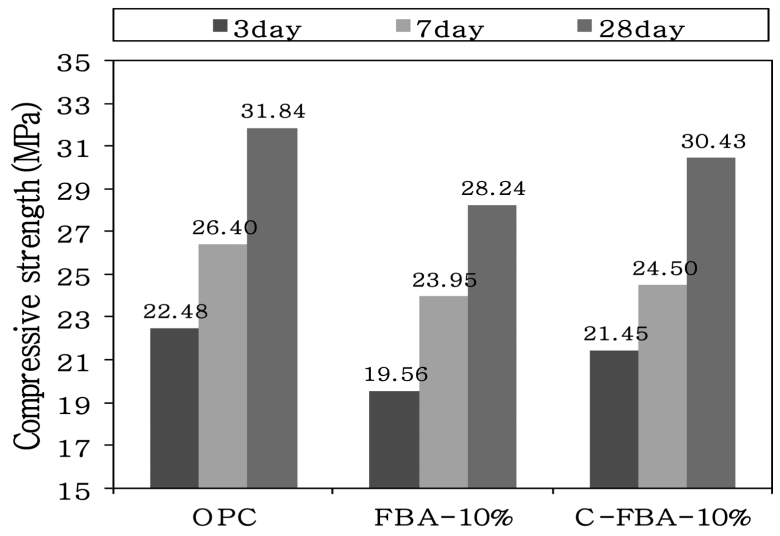

(b) Compressive strength of mortar 
$88 \%$ and approximately $95 \%$ of that value of the OPC mortar. On the other hand, the long-term compressive strength of the C-FBA-mixed mortar may recover as the OPC hydrate $\left(\mathrm{Ca}(\mathrm{OH})_{2}\right)$ and the small amount of pozzolan materials (silicate or aluminate) existing in the C-FBA undergo a reaction to produce a hydration product (C-S-H gel).

\section{Conclusions}

In the present study, to increase the applicability of FBA, free $\mathrm{CaO}$ contained in FBA was converted to a $\mathrm{Ca}$ compound, $\mathrm{CaCO}_{3}$, under appropriate carbonation conditions; the carbonated FBA was mixed with OPC and the properties of the resulting FBA-mixed OPC were measured. The following conclusions can be drawn from the present study.

1) The rate of reactants, which was measured to verify the reactivity of FBA with an aqueous carbonate solution, remained in a range from $4.5 \%$ to $4.7 \%$ at ratios of the aqueous carbonate solution over $30 \%$, indicating that $30 \%$ may be an appropriate ratio of the aqueous carbonate solution.

2) Regardless of the kind of carbonate involved in the carbonation of FBA, the intensity of the $\mathrm{CaCO}_{3}$ peak increased for $1 \mathrm{~h}$ and then remain constant, indicating that the appropriate reaction time for the FBA carbonation may be $1 \mathrm{~h}$.

3) As the molar concentration of the aqueous carbonate solution increased, the yield of $\mathrm{CaCO}_{3}$ increased. The highest $\mathrm{CaCO}_{3}$ yield was found to be $27.8 \mathrm{wt} \%$ when the carbonation was performed using a $3 \mathrm{M}$ aqueous $\mathrm{K}_{2} \mathrm{CO}_{3}$ solution.

4) Measurement of the properties of the mortars prepared by mixing $10 \%$ of the conventional FBA and the C-FBA with OPC showed that the water absorption of the C-FBA-mixed mortar was lower by 0.045 than that value of the FBA- mixed mortar. At the material age of 28 days, the compressive strength of the C-FBA-mixed mortar was about $95 \%$ of that of the OPC mortar.

\section{Acknowledgements}

The present study was financially supported by the 2015 Industry-Academy-Research Cooperation Technology Development Project (Grant No. C0350587) of the Small and Medium Business Administration.

\section{REFERENCES}

1. J. H. Maeng, T. Y. Kim, and D. H. Seo, "Minimizing Environmental Impact in Accordance with the Thermal Power Plant Ash Management (1)," KEI, ISBN 978-89-8464-904$0,2014$.

2. E. D. Jeong, Co-Combustion Characteristics of Mixed Coal with Anthracite and Bituminous in a Circulating Fluidized Bed Boiler (in Korean), pp. 1-12, in M. S. Thesis, Hanyang Uiniversity, Ansan, 2010.

3. H. S. Park, Rheological Properties of Portland CementBlast Furnace Slag-Fly ash Blends (in Korean), pp. 1-4, in M. S. Thesis, Dankook University, Yongin, 2008.

4. S. J. Han, D. K. Kim, J. H. Lee, S. H. Park, and J. H. Wee, "Capture of Carbon Dioxide Emitted from Coal-Fired Power Plant Using Seawater,” J. Kor. Soc. Environ. Eng., 35 [5] 340-49 (2013).

5. J. S. Sim, K. G. Lee, Y. T. Kim, and S. K. Kang, "Hydration Characteristics of Coal-Fly Ash Containing High $\mathrm{CaO}$ Compound," J. Korean Ceram. Soc., 49 [2] 185-90 (2012).

6. G. H. Sheng, Q. Li, and J. P. Zhai, "Investigation on the Hydration of CFBC Fly Ash," Fuel, 98 61-6 (2012). 